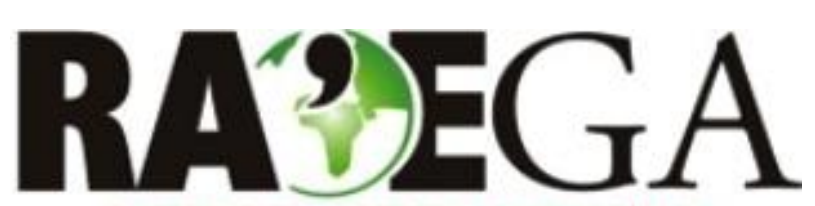

O ESPACYO GEOGRÁFICO EM ANÁLISE

\title{
AS DINÂMICAS DA RELAÇÃO ENTRE COMÉRCIO E INDÚSTRIA EM FRANCA (SP)
}

\section{THE DYNAMICS OF THE RELATIONSHIP BETWEEN TRADE AND INDUSTRY IN FRANCA (SP)}

\author{
Judite de Azevedo do Carmo \\ Universidade do Estado de Mato Grosso - UNEMAT \\ Cáceres, MT, Brasil \\ e-mail: juditeacarmo@gmail.com
}

Silvia Aparecida Guarnieri Ortigoza Universidade Estadual Paulista - UNESP

São Paulo, SP, Brasil

e-mail:sago@rc.unesp.br

Recebido em: 11/05/2015

Aceito em: 25/07/2016

\section{Resumo}

Objetiva-se, neste texto, a retomada de parte dos resultados de uma pesquisa desenvolvida por Carmo (2012) sobre o Arranjo Produtivo Local (APL) de Franca, São Paulo, especializado na produção de calçados masculinos. A ideia central deste artigo foi construir uma análise das dinâmicas da relação estabelecida entre comércio e indústria, na contemporaneidade, destacando as questões teóricas inerentes ao tema. Além disso, o artigo busca 0 entendimento de que há uma necessidade de reflexão que procure desvendar as articulações do comércio na dinâmica da produção em APL, haja vista que o mesmo desempenha papel de grande relevância por intermédio de suas estratégias, as quais podem desencadear uma maior demanda de produção. A análise proposta permitiu o esclarecimento de que as transformações ocorridas no processo produtivo, nas décadas finais do século $X X$, condicionaram 0 estreitamento das relações entre a indústria e o comércio, sendo que ambas as atividades são realizadas em dependência mútua e que no APL, em destaque, a relação entre as indústrias e o comércio local deve ser ampliada, pois foi observada a existência de um monopólio da comercialização dos sapatos pelas indústrias calçadistas por meio de lojas próprias ou franquiadas, havendo pouca relação com os estabelecimentos comerciais de terceiros.

Palavras-chave: Produção; Varejo especializado; Arranjo Produtivo Local; Novas Estratégias Comerciais. 


\begin{abstract}
The objective of this text is a reassessment of part of the results of a study developed by Carmo (2012), which considers the local productive arrangement (LPA) specialized in the production of men's footwear in Franca, São Paulo. The central idea of this article was to construct an analysis of the dynamics of the current relationship established between trade and industry, highlighting the theoretical questions inherent to the theme. Furthermore, the article explored the understanding that reflection is needed to unveil the articulations of the market in the production dynamics of LPA, given that the market plays a vital role via its strategies, which can trigger greater production demand. The proposed analysis permitted the clarification of the transformations that occurred in the production process during the final decades of the $20^{\text {th }}$ century, which conditioned the tightening of relations between the industry and the market, as both activities are performed in mutual dependence; and in the LPA, highlighted here, the relationship between the industries and the local market should be expanded, given the observed existence of a monopoly on the marketing of shoes by the shoe industries through their own shops or franchises, having little relationship with third-party commercial establishments.
\end{abstract}

Keywords: production; Specialized retail; Local Productive Arrangement; New Marketing Strategies.

\title{
1. INTRODUÇÃO
}

A indústria e o comércio passaram por importantes transformações que se acentuaram a partir das últimas décadas do século $X X$. Na atividade industrial, percebe-se que as mudanças não só ocorreram na produção, mas foram também incorporadas à toda sua cadeia de valor, "desde a concepção do produto até seu consumo final" (CARMO, 2012, p.20).

O comércio apresentou grande expansão nesse período, principalmente com a implantação de grandes empresas comerciais, bem como com as novas estratégias para o domínio do mercado consumidor. Essas novas estratégias adotadas pela atividade comercial, de acordo com Ortigoza (1996), são constantemente aperfeiçoadas, com o intuito de expandir as cadeias de distribuição, para que as vendas se elevem, assim como o lucro, consequentemente.

A indústria e o comércio estreitaram suas relações, uma vez que a produção flexível exige a identificação das necessidades dos consumidores para ofertar os produtos, de forma que o ciclo da produção não seja interrompido, destarte os estudos que procuram desvendar essa relação são 
de suma relevância, já que, na atualidade, as atividades industrial e comercial realizam-se em condições de dependência mútua.

O APL calçadista de Franca é exemplar para demonstrar a importância da relação comércio-indústria, pois as informações levantadas, na pesquisa empírica realizada por Carmo (2012), reafirmaram que o crescimento da produção, o desenvolvimento do setor e as expressividades das marcas são dependentes de forma direta da expansão do comércio e do aperfeiçoamento das estratégias de vendas.

As relações comércio-indústria, ora mencionadas, são estabelecidas no espaço, uma vez que este é o produto e a condição para que elas se realizem. Por meio deste texto, portanto, procura-se retomar partes do resultado da pesquisa desenvolvida por Carmo $(2012)^{1}$ sobre o Arranjo Produtivo Local de calçados masculinos de Franca (SP), a qual objetivou esclarecer as dinâmicas da relação estabelecida entre o comércio e as indústrias calçadistas.

A proposta deste texto justifica-se em razão do entendimento de que há uma necessidade de reflexão, que procure desvendar as articulações do comércio na dinâmica da produção em APL, haja vista a atividade comercial desempenhar papel de grande relevância para o processo produtivo, uma vez que por intermédio de suas estratégias se dá o desencadeamento de demanda para a produção.

\section{MATERIAIS E MÉTODOS}

Para o desenvolvimento da pesquisa, recorreu-se ao "materialismo histórico e dialético", devido a sua capacidade "de assinalar as causas e as consequências, dos problemas, suas contradições, suas relações, suas qualidades, suas dimensões quantitativas, se existem, e realizar através da ação um processo de transformação da realidade que interessa" (TRIVIÑOS, 1987, p.125).

\footnotetext{
${ }^{1}$ Pesquisa de doutorado no âmbito do Programa de Pós-Graduação em Geografia, "área de concentração em Organização do Espaço", no Instituto de Geociências e Ciências Exatas, da UNESP/Rio Claro, sob financiamento do CNPq.
} 
Ao adotar esse método, pressupõe-se que "a análise deve sempre captar corretamente essa relação complexa, contraditória, dos momentos entre si e com a totalidade" (LEFEBVRE, 1995, p. 119), isto porque, os objetos e os fenômenos não existem isoladamente na natureza, sendo que um está em constante ligação com o outro, num momento condicionando e em outro sendo condicionado. Esse método foi o que possibilitou a análise espaço-temporal do Arranjo Produtivo Local em tela.

Os dados utilizados para a análise, em grande parte, foram coletados por Carmo (2012), por meio dos seguintes procedimentos:

Entrevista realizada com a representante do Sindifranca, instituição que possui grande atuação na governança do APL; com a gerente de marketing do shopping do calçado e com a Assessora da Secretaria de Finanças da Prefeitura Municipal de Franca.

Questionário aplicado de forma direta aos gerentes dos estabelecimentos comerciais de varejo especializado de Franca e de forma indireta (via e-mail, opção dada pelas indústrias) às indústrias de calçados de Franca e à representante do departamento de marketing da feira Francal (Feira Internacional de Calçados, Acessórios de Moda, Máquinas e Componentes).

Além dos dois procedimentos técnicos mencionados, Carmo (2012) também procedeu ao levantamento de dados e informações em órgãos institucionais como o Instituto de Estudos e Marketing Industrial (IEMI, 2011), Sindicato das Indústrias de Calçados de Franca (SINDIFRANCA, 2011), no Instituto Brasileiro de Geografia e Estatística (IBGE), bem como na Fundação Sistema Estadual de Análise de Dados (SEADE), em busca de informações sobre o Índice Paulista de Responsabilidade Social (IPRS) ${ }^{2}$.

Os dados obtidos junto ao IEMI serviram para a análise quantitativa em nível de APL, enquanto aqueles obtidos por meio de questionários aplicados a 12 indústrias locais foram a base da análise qualitativa, em nível de indústria.

\footnotetext{
2 O IPRS - Índice Paulista de Responsabilidade Social, segundo o Site da Assembleia Legislativa, objetiva "facilitar uma identificação mais ágil das necessárias políticas públicas a serem implementadas nos municípios paulistas, tendo, a exemplo do IDH, o ser humano sempre no centro do processo de seu desenvolvimento".
} 
Os questionários aplicados aos estabelecimentos comerciais possibilitaram a análise da relação indústria e comércio.

A pesquisa bibliográfica foi utilizada na realização deste texto para embasamento da reflexão teórica, dos conceitos trabalhados na geografia, especificamente na Geografia Urbana, do comércio e da indústria, bem como para a coleta de dados em estudos desenvolvidos sobre o tema e sua área de pesquisa.

\section{RESULTADOS E DISCUSSÕES}

\subsection{Indústria e Comércio: Transformações e Intensificação das Inter- relações}

As décadas finais do século $X X$ registraram a decadência do modelo de produção fordista em consonância com a crise enfrentada pelo próprio capitalismo. Para Harvey (1992), a rigidez dos investimentos de capital fixo em larga escala e de longo prazo, dos mercados e dos contratos de trabalho, dos compromissos do Estado no que se refere à assistência e seguridade social para manter a sua legitimidade, são os principais fatores que contribuíram tanto para a crise do fordismo quanto do capitalismo.

Os anos de 1970 e 1980, ainda segundo Harvey (1992), foram de grande perturbação econômica e de encaminhamento na direção de uma reestruturação produtiva e de reajustamento social e político, à medida que uma série de novas experiências começou a tomar forma na organização industrial.

Dessa forma, o novo regime de acumulação começa a estabelecer-se a partir da década de 1970 e passa a apresentar importantes mudanças, tanto estruturais quanto organizacionais, na atividade industrial, além das mudanças espaciais, sobre as quais Benko (1996, p. 29) coloca que passam a requerer flexibilidade nos processos de produção, no desenvolvimento dos produtos, bem como na regulação das relações de trabalho.

O autor supracitado (1996, p. 29) ainda explica que a desintegração vertical das relações de proximidade entre dirigente e subcontratante, bem como a contínua troca de informações, é gerada por uma maior flexibilidade. A 
proximidade espacial, segundo o referido autor, contribui também para a interação e a regulação final do processo de produção global.

A reestruturação produtiva pode ser observada quando se identifica na indústria uma profunda divisão técnica e social do trabalho, que é resultante de um sistema produtivo simultaneamente fragmentado e integrado (MENDES, 1997). Em razão dessas transformações torna-se possível a identificação da existência de várias formas de organização da produção, bem como ficam perceptíveis, em um mesmo lugar, diferentes regimes e modalidades de produção.

Essas constatações permitem chegar à conclusão de que a implantação do modelo de acumulação flexível não implica em uma ruptura total com a produção fordista, ou seja, o surgimento de um não corresponde ao fim do outro.

Com o novo modelo de produção flexível se instalando, a capacidade de acompanhar a evolução da tecnologia tornou-se o principal fator de competitividade, desta feita, as vantagens tradicionais ${ }^{3}$ (absolutas), baseadas apenas no menor custo de produção de determinado bem, perderam importância em relação às vantagens comparativas ${ }^{4}$, que são baseadas na relativa eficiência na produção de determinado bem.

Diante do surgimento do modelo de produção citado acima, Sampaio (2009) explica que o conceito de aglomeração industrial voltou a integrar o rol de temas de interesse nas investigações acadêmicas, principalmente no que diz respeito àquelas que incorporaram em suas abordagens as forças aglomerativas e o território local, como escala para as intervenções, tanto políticas quanto econômicas, para o desenvolvimento local.

As aglomerações industriais favorecem um novo dinamismo econômico à localidade onde são inseridas e, segundo Sampaio (2009, p. 72), elas são "as

\footnotetext{
${ }^{3}$ A Teoria das vantagens tradicionais foi elaborada por Adam Smith e encontra-se em sua obra "A Riqueza das Nações: Investigação sobre sua natureza e suas causas" publicada em 1776, título original: An Inquiry into the Nature and Causes of the Wealth of Nations.

${ }^{4}$ A teoria das vantagens comparativas ou relativas foi elaborada por David Ricardo em 1820 em sua obra "Princípios de Economia Política e Tributação", título original: On the Principles of Political Economy and Taxation.
} 
principais fontes de crescimento econômico em todos os estágios de desenvolvimento".

As aglomerações de indústrias de variados portes, envolvidas na produção de determinada mercadoria, no Brasil, são denominadas de Arranjo Produtivo Local, porque autores como Cassiolato e Lastres (2000, 2001) entendem que elas, apesar de serem um tipo específico de Cluster, quando em desenvolvimento, apresentam características específicas.

O Cluster, conforme Lastres e Cassiolato (2005), são aglomerações territoriais de empresas com características similares, que enfatizam, em alguns casos, mais a concorrência que a cooperação. A importância da inovação é mais entendida como aquisição de equipamentos e não contempla necessariamente outros atores, além das empresas, tais como organizações de ensino, pesquisa e desenvolvimento, dentre outros.

Já Arranjo Produtivo Local para Cassiolato e Lastres (2000, p. 15) são:

Aglomerações territoriais de agentes econômicos, políticos e sociais - com foco em um conjunto específico de atividades econômicas - que apresentam vínculos mesmo que incipientes. Geralmente envolvem a participação e interação de empresas - que podem ser desde produtoras de bens e serviços finais até fornecedoras de insumos e equipamentos, prestadoras de consultorias e serviços, comercializadoras, clientes, entre outros, e suas variadas formas de representação e associação. Incluem também diversas outras instituições públicas e privadas voltadas para formação e capacitação de recursos humanos (escolas técnicas e universidades), pesquisa, desenvolvimento, engenharia, política, promoção e financiamento.

Portanto, o que vai diferenciar Cluster de APL, analisando os conceitos apresentados por Cassiolato e Lastres, é o não envolvimento, no primeiro, de outros atores, como Universidades, por exemplo, o que já acontece no APL.

A articulação entre os diversos atores de determinado território, como as indústrias envolvidas no processo produtivo, as empresas de comercialização e as várias instituições, sejam elas públicas ou privadas, quando proporcionada pelo APL, faz com que este seja importante para o alcance do desenvolvimento local e regional, isto porque, segundo (CARMO, 2012), através dessas 
articulações, novas redes e estruturas são criadas, novos espaços são produzidos, visando atender a demanda do Arranjo Produtivo.

Verdi e Pires (2008) argumentam que Arranjo Produtivo Local é uma forma específica de organização de empresas que, em alguns países, têm significativa importância para o desenvolvimento local.

Cassiolato e Lastres (2000) defendem que os APLs são importantes para os países em desenvolvimento, uma vez que eles têm auxiliado pequenas e médias empresas a ultrapassarem barreiras ao crescimento da firma e, com isso, vem ganhando importância as análises que os focalizam, haja vista possibilitarem o exame de suas formas de articulações, bem como de suas dinâmicas, por entender que delas se origina sua força competitiva, bem como a da localidade onde se inserem.

Como pode ser verificado pelas colocações realizadas até o momento, o processo produtivo apresentou grandes modificações nas últimas décadas. $O$ comércio, assim como a indústria, também não ficou imune a essas transformações importantes, cuja identificação é possível no âmbito das atividades comerciais.

O comércio, conforme explica Salgueiro (1996, p.1), "é uma fase intermediária entre a de produção de bens ou serviços e a de seu consumo e utilização, tendo por função levar/disponibilizar as mercadorias até os consumidores". Sobre as transformações verificadas na atividade comercial no decorrer do tempo, Teixeira (2000) explica que houve grandes mudanças desde a loja de bairro, cujo comerciante residia nos fundos com sua família, e onde o cliente era atendido pessoalmente, e mesmo fora do horário de funcionamento, até as novas lojas que passaram a incorporar princípios fordistas no atendimento, na exposição de mercadorias, no estoque e nas compras.

Com o surgimento do modelo de acumulação flexível, evidencia-se também o afloramento de um novo modo de consumo. Benko (1996, p. 29) expõe que com a passagem para um novo regime de acumulação, mudanças fundamentais ocorrem "nos modos de produção e de consumo, nos mecanismos institucionais de regulação das relações sociais". 
Tais mudanças, ainda conforme o entendimento do autor anteriormente citado, induzem a uma reestruturação espacial da sociedade inteira, a uma redefinição do conteúdo ideológico dos espaços, assim como estabelecem uma nova divisão social e espacial do trabalho, bem como uma criação de novos espaços de produção e de consumo.

Pintaudi (1992), sobre as mudanças no comércio, explica que estas foram possíveis graças à produção em massa, ao aumento da concentração populacional urbana, à elevação tanto quantitativa quanto qualitativa do consumo e à generalização do uso do automóvel, este último, certamente, é um dos principais fatores que favoreceram a redefinição dos locais de compra.

As transformações detectadas no comércio não ocorreram somente nas estruturas comerciais, mas também nas estratégias de vendas; novas formas de comércio e de consumo foram se estabelecendo com o objetivo de elevar a acumulação, ou seja, o lucro.

Em Franca como o industrial toma para si todas as fases das operações para a realização da mercadoria, ele perde, em partes, a aceleração da rotação de seu capital, mas ao mesmo tempo, acaba dominando todo o processo desde a produção ao consumo. Esse domínio possibilita ao industrial controlar as operações da circulação das mercadorias e, também, não precisa ceder ao comerciante certa parte da mais-valia, assim, o lucro fica todo sobre o seu controle.

Seguindo com a explanação das mudanças nas estratégias comerciais, o autosserviço merece destaque. Cleps (2005) explica que este se restringia ao comércio de mercearias; mas, com o decorrer do tempo, foi incorporado aos outros setores do comércio varejista como o de livros, discos/CDs, artigo de vestuário, ferragens, bancos, bibliotecas, restaurantes, entre outros.

A mesma autora chama a atenção para o fato de que, com o surgimento dessas novas formas de comercialização, o comércio tradicional não desapareceu. Em algumas cidades pequenas, ele continua a se perpetuar, e com grande relevância. Em outras cidades, até mesmo nas médias e grandes, ele reapareceu em alguns bairros como um comércio extremamente elitizado. 
O autosserviço atribuiu um novo significado à mercadoria, que agora, exposta nas prateleiras, facilita-lhe o alcance do consumidor. Entretanto, para seu consumo, foi necessário também criar-lhe a necessidade. Então, ela passou a representar um objeto de investimento, de paixão, de fascinação e de projeção, qualificando e enredando o seu dono/consumidor (CLEPS, 2005). À mercadoria, além de valor de uso, também foi incorporado um grande valor de troca, assim como uma grande carga simbólica.

Ao identificar, na sociedade atual, a elevada carga simbólica presente na mercadoria, Baudrillard (1995) defende que esta, além de ser objeto de produção, imprime uma ordem de consumo que é manifesta como ordem da manipulação dos signos. Portanto, em razão das características dessa sociedade, Baudrillard (1995) a denomina de "Sociedade do Consumo", e explica que para este se realizar, é preciso apenas que os consumidores sintam a necessidade da mercadoria-símbolo, símbolo de status, de poder.

Cachinho (1999, p. 168) expõe que "o consumidor torna-se um verdadeiro actor e o consumo uma manifestação simbólica e comunicacional”, salientando ainda que "o poder simbólico do consumo diz tanto respeito às mercadorias como aos lugares erigidos em seu nome", ou seja, aos diferentes espaços de consumo.

Em relação às necessidades de consumo, as ideias de Lipovetsky (1989) são contrárias às de Baudrillard (1995). Para o primeiro, com a explosão da moda consumada, as pessoas consomem não para obter prestígio social, mas com o objetivo de satisfação individual, indiferente à opinião dos outros. Dessa forma, o consumo apresenta uma ordem individualista.

Para o referido autor, não se deve interpretar, por meio da lógica social, da diferença e da distinção, "a paixonite rápida" das classes médias e populares pelo "videocassete" ou pela "prancha a vela", pois o que está em evidencia nesta relação é:

A sede de imagens e espetáculos, o gosto pela autonomia, o culto do corpo, a embriaguez das sensações e do novo. Consome-se cada vez menos para ofuscar o outro e ganhar consideração social e cada vez mais para si mesmo [...] (LIPOVETSKY, 1989, p.173). 
Mesmo assumindo posição divergente à de Baudrillard (1995), Lipovetsky (1989) ressalva que os objetos possuem realmente significantes sociais e signos de inspiração, mas não se pode afirmar que o consumo de massa é comandado pela necessidade de distinção de status, explicando ainda que esta sua afirmação não implica dizer que os objetos estão livres de valor simbólico, assim como o consumo está livre da competição por status, ao contrário, em inúmeros casos, é possível identificar a compra de algum objeto como um desejo de demarcação social.

Entretanto, adverte o autor, esse tipo de consumo não pode ser adotado como referência de um consumo de massa, isto porque o objetivo principal é a aquisição de prazer e de uso funcional, pois ao consumir os objetos, as pessoas sentem que estão consumindo "dinamismo, elegância, poder, renovação de hábitos, virilidade, feminilidade, idade, refinamento, segurança, naturalidade" (LIPOVETSKY, 1989, p.174), tudo isso para a sua satisfação individual.

Como pode ser observado, inúmeras são as imagens que influenciam o consumidor e, por isso, segundo Lipovetsky (1989, p. 174), seria "simplista reduzir [o consumo] só aos fenômenos de vinculação social quando precisamente os gostos não cessam de individualizar-se".

Verifica-se então, na atualidade, uma necessidade dos produtores de moda, dos criadores de produtos, assim como dos fabricantes atuarem de maneira a obter a elevação do nível do consumo; porém, o grande problema enfrentado pelo capitalismo contemporâneo, conforme Baudrillard (1995), é vender a variedade de produtos fabricados. Para isto, a solução encontrada é a criação e a manipulação das necessidades, pois não é suficiente somente controlar a produção das mercadorias, deve-se ter também o controle de seu consumo.

Dessa forma, o mesmo autor infere que as ações de sondagens, estudos de mercado (anteriores à produção), de publicidade, marketing, condicionamento (posterior à produção), tiram do consumidor o seu poder de decisão e o transfere para a empresa, que poderá manipulá-lo da forma que Ihe convier. 
A publicidade, de acordo com Carmo e Ortigoza (2010), é o instrumento por meio do qual as necessidades são criadas diariamente. As autoras explicam que a publicidade de novos produtos ou de novas marcas, assim como as mesmas marcas com novas publicidades, são divulgadas por diferentes meios de comunicação e que as diversas estratégias utilizadas fazem com que os produtos assumam uma característica de efêmero e transmitam de forma indireta aos consumidores uma mensagem de que, caso não realizem o consumo, tornar-se-ão obsoletos como os produtos.

Neste contexto, os produtores de moda (os idealizadores de novos produtos), são atentos às características atuais da sociedade, pois como especifica Baudrillard (1995), anteriormente bastava produzir as mercadorias, o consumo era uma consequência natural; atualmente é preciso mais que isto, é preciso produzir os consumidores. Antes da produção em si, faz-se necessário criar, produzir a demanda.

A partir das leituras das obras citadas, torna-se possível o entendimento de que o comércio é um momento do ciclo da produção que apresenta, hoje, uma relevância indiscutível. Por seu intermédio, as mercadorias são levadas ao consumidor e são suas estratégias de merchandising que thes manipulam os desejos e lhes criam as necessidades, de modo a elevar o consumo.

Portanto, conforme Carmo (2012), é possível dizer que na atualidade a indústria está intimamente ligada ao setor terciário (comércio e serviço), intensificando a relação de dependência mútua, principalmente em razão da diversidade de produtos disponíveis e da individualização crescente dos gostos dos consumidores.

Isto pode ser observado quando os empresários industriais começaram a intensificar suas relações com os agentes envolvidos com o comércio e com sua distribuição, com o objetivo de identificar as necessidades dos consumidores para atuarem na oferta de produtos que satisfaçam seus desejos e, consequentemente, obtenham sucesso nos mais diversos mercados.

Carmo (2014) expõe que os aglomerados produtivos, para sobressaírem-se também não podem ignorar esse movimento e devem, por meio de sua governança, desenvolver um setor de comércio de forma 
estruturada, que desempenhe funções de interlocutor, favorecendo a elaboração do produto condizente com as necessidades e desejos dos consumidores finais. Diante de tais constatações, entende-se que os processos iniciais e finais da cadeia de valor devem ser valorizados e não somente o processo produtivo.

\subsection{A Relação entre Indústria e Comércio no Arranjo Produtivo Local de Franca (SP)}

Os estudos realizados, tanto sobre a indústria, quanto sobre o comércio, demonstram que, como consequência da crescente racionalidade em ambos os processos, é cada vez mais difícil analisá-los de forma separada, o que ficou bem evidenciado no resultado da pesquisa realizada no Arranjo Produtivo Local de Franca, cuja expansão do mercado e, consequentemente, do comércio é que possibilitou seu desenvolvimento no decorrer do tempo.

A atividade com o couro inicia-se no município, já nas primeiras décadas do século $X X$, sendo seu principal objetivo atender o mercado local com produtos como arreios, selas, bainhas, sapatões, dentre outros. A demanda por tais produtos era decorrente da presença, no espaço local, de tropeiros que vinham de Goiás e do Mato Grosso, em razão de Franca localizar-se em uma rota que ligava tais regiões aos mercados do sul.

A instalação de uma fábrica para a produção de calçados aumentou a oferta do produto no município; porém, foi somente com o estabelecimento de novas unidades produtivas especializadas na confecção de sapatos, que houve a ampliação da atividade na localidade.

A ampliação da oferta de calçados direcionou as buscas por outros mercados que não o local, este que, em princípio, era o principal consumidor, chegando ao mercado regional e, posteriormente, ao nacional, ficando o primeiro com pequena representatividade no total das vendas.

A especialização do município na produção de calçados, juntamente com a expansão da atividade, proporcionou à comercialização alcançar o mercado internacional. O desenvolvimento e a consolidação do APL estão intimamente ligados a sua atuação nos diversos mercados, ou seja, a sua 
expansão e ao alcance do comércio de seus produtos.

Verifica-se, conforme dados do IEMI (2011), que a distribuição dos calçados do APL é realizada majoritariamente por meio do comércio varejista especializado (estabelecimento comercial de venda a varejo, ao consumidor, especializado em um determinado produto) e da exportação, o que pode ser observado na tabela (1).

Tabela 1: Principais Canais de Distribuição Utilizados no APL de Franca (SP) em 2009

\begin{tabular}{lc}
\hline Canais de Distribuição & Valor (\%) \\
\hline Varejos especializados & 75,1 \\
Varejo não & 9,5 \\
especializado & \\
Comércio atacadista & 0,3 \\
Lojas de pronta-entrega & 1,7 \\
Outros & 1,3 \\
Exportação & 12,0 \\
\hline
\end{tabular}

Fonte: IEMI (2011)

Elaborado por Carmo (2012).

As exportações, segundo o IEMI (2011), são realizadas individualmente pelas indústrias, por meio de agentes de importação ou de representantes, sendo que mais da metade, $53 \%$ das indústrias, atua no mercado externo, com marcas próprias. Quando se analisou o volume exportado, identificou-se que há pouca diferença entre as que exportam com marcas próprias e as que exportam com marcas de clientes.

Exportar com marcas de clientes possui algumas desvantagens, como por exemplo, ter que fabricar os produtos com especificações do comprador, retraindo a criatividade do produtor e as chances de criação e de gestão de marca, bem como impossibilita a divulgação do APL, haja vista as origens do produto serem identificadas somente por meio do "made in Brazil". Outra desvantagem é que por intermédio desse tipo de exportação não há o estabelecimento de fidelidade do cliente, pois o produtor pode ser trocado.

Há que se dizer que o mercado interno é propício ao estabelecimento de liberdade das indústrias em atuarem com suas próprias marcas, mas o percentual das que atuam com marcas de terceiros ainda é grande. Estas são 
geralmente indústrias de dimensões de micro a pequena, sem recursos financeiros suficientes para investirem na criação e na gestão de marcas, bem como em design e moda.

Diante disso fica evidente a necessidade de estabelecimento de cooperação entre elas para que possam superar tal barreira, e mais que isto, faz-se necessário o estabelecimento de ambiente de confiança e o entendimento, por parte de todos, de que certas ações proporcionam ganhos em comum.

O comércio varejista, de acordo com Carmo (2012) é o mais importante canal de distribuição utilizado pelas indústrias e seu principal articulador é o representante comercial. Este realiza visitas às lojas e, por meio de catálogo, com os modelos de calçados, realiza a publicidade do produto.

A mesma atora expõe que algumas indústrias utilizam agências de representação comercial, que agregam pessoal treinado e que esta estratégia possui maiores garantias de sucesso; entretanto, ressalta que tal atitude reduz o contato do produtor com o consumidor final, sendo que esse contato de extrema relevância na atualidade, como já especificado linhas acima. Ele possibilita a identificação das demandas e dos desejos do consumidor.

A criação de canais próprios para distribuição dos produtos, nos mais diversos mercados, é ressaltada por Carmo (2012), como sendo de suma importância para o crescimento da indústria; entretanto, mantê-los é algo dispendioso. Contudo, Suzigan, Garcia e Furtado (2005) são categóricos ao defender que o domínio dos ativos comerciais relacionados à posse da marca, bem como da distribuição do produto, contribui para a incorporação da inovação e da criatividade, em todos os momentos da produção, cuja ação pode ser considerada como essencial para 0 desenvolvimento e a consolidação da indústria no mercado.

Foi identificado na pesquisa de Carmo (2012) que os Estados Unidos da América são o principal mercado consumidor dos calçados do APL, no exterior; enquanto, no mercado interno, é a região sudeste, a mais desenvolvida do país, sendo, portanto, onde se localiza a população com maior poder aquisitivo. 
Tal identificação leva ao entendimento de que essa região é a mais importante consumidora dos calçados de Franca no Brasil, em razão do calçado produzido no APL possuir um valor elevado, portanto consumido, em maior proporção por indivíduos pertencentes às classes $B$ e $C^{5}$.

O valor elevado do calçado é justificado por sua produção ser realizada de forma a utilizar, como principal matéria prima, o couro e a mão de obra especializada, bem como devido ao fato de alguns modelos possuírem acabamento manual, favorecendo a valorização do produto e a consequente elevação de seu preço.

O alcance da qualidade e a valorização do produto devem ser almejados pelas indústrias do APL; para tanto, faz-se necessária a incorporação de suas inovações, pois assim se poderá buscar uma maior inserção entre os consumidores pertencentes à classe $\mathrm{A}$, os quais exigem design arrojados, exclusividade e luxo, bem como o seguimento das tendências da moda, haja vista poderem pagar por isto.

Esta questão deve ser considerada, destarte a China se consolidar na atualidade como uma forte concorrente para as indústrias calçadistas brasileiras, sendo os seus calçados adquiridos especialmente entre os consumidores de Classe $\mathrm{C}$ e E. Em tais condições, os industriais de Franca devem investir na qualidade de seus produtos para alcançar os segmentos de maior poder aquisitivo, aqueles da Classe A, uma vez que no quesito preço fica quase impossível competir com a China.

Verificou-se na pesquisa de Carmo (2012) que o mercado local é pouco expressivo para as indústrias de calçados de Franca. Nos estabelecimentos comerciais especializados e localizados nas ruas do centro, a porcentagem de calçados de produção local é pequena e a principal justificativa para isto, de acordo com os lojistas, é a de que a procura é maior pelos modelos femininos, sendo que a produção local é especializada em modelos masculinos. Porém, em Franca, também se verifica a produção de calçados femininos.

\footnotetext{
${ }^{5}$ De acordo com o IBGE, a classificação da população em classes sociais segue basicamente o critério abaixo: Classe A: Rendimento mensal acima de 30 salários mínimos; Classe B: De 15 a 30 salários mínimos; Classe C: De 6 a 15 salários mínimos; Classe D: De 2 a 6 salários mínimos; Classe E: Até 2 salários mínimos.
} 
Quando os comerciantes foram indagados sobre essa questão, justificaram que os modelos femininos produzidos em Franca são de griff, tendo, por isso, um preço muito elevado e consequentemente pouca saída no mercado local.

Em análise ao Planejamento Estratégico do Setor Calçadista de Franca, Carmo (2012) verificou que alguns representantes comerciais de grandes redes varejistas possuem a seguinte opinião sobre a maioria dos calçados femininos produzida em Franca: possui uma boa qualidade, embora o conforto e o acabamento não agradem muito às consumidoras; além disso, é pouco atrativo, exatamente pelo design que apresenta. Contudo, ainda possui preço elevado. A autora destaca que a opinião desses representantes comerciais vai ao encontro à dos lojistas locais.

Diante do exposto, a autora supracitada conclui que no momento de providenciar o abastecimento da loja com os modelos femininos, os lojistas dão preferência aos fornecedores de APLs especializados na produção desses calçados, como os de Novo Hamburgo (RS) e de Jaú (SP), por exemplo.

É possível entender então que os comerciantes estão à procura de calçados femininos, com preço acessível e com boa qualidade, os quais são encontrados nos APLs citados acima. Porém, o APL de Franca é especializado em calçados masculinos, mas estes, segundo levantamento de Carmo (2012), também estão em menor porcentagem nos estabelecimentos comerciais do centro.

Assim, a autora citada, procura entender o por quê desta situação, haja vista, em se tratando de produção local, deduz-se que seria mais fácil e vantajoso para os lojistas realizarem a encomenda desses modelos no próprio município, sendo que, além disso, o custo com o transporte seria muito mais baixo. Portanto, primeiramente buscou verificar se o problema estava relacionado à qualidade do calçado.

Novamente a leitura do Planejamento Estratégico por Carmo (2012), proporcionou a mesma identificar que os representantes comerciais de grandes redes varejistas elogiam o calçado masculino produzido em Franca e dizem 
que ele se destaca daquele produzido em outros APLs, em razão de possuir excelente qualidade, design moderno, marcas conhecidas e preço justo.

Tal identificação originou ainda mais inquietações na autora sobre a ausência do produto nos estabelecimentos de comércio especializado do centro. Ciente das qualidades do calçado produzido em Franca e do seu reconhecimento pelos representantes comerciais, a sua atenção foi dirigida para o principal mercado consumidor do APL, a região sudeste, e para alguns dados sociais obtidos sobre o município em foco.

Por meio de tal procedimento, Carmo (2012) aprofundou sua reflexão, chegando a conclusão de que uma das causas da inexpressividade da presença do calçado de produção local nesses estabelecimentos se dá pelo fato de seu preço não ser compatível com o poder aquisitivo da população local.

A chegada à essa conclusão pela autora foi possível ao identificar, em análise ao Índice Paulista de Responsabilidade Social (IPRS), para o qual Franca apresenta o índice 3, cuja indicação é a de que seu nível de riqueza é baixo, apesar de, em outros indicadores, possuir bons resultados.

Indo além nessa reflexão, Carmo (2012) apresenta mais um fator que explica a pequena porcentagem de calçados de produção local encontrados nos estabelecimentos comerciais especializados e localizados nas ruas do centro, qual seja: o controle exercido pela indústria na distribuição do calçado no mercado local, distribuição esta que se realiza por meio de loja própria ou de venda direta na fábrica.

Nas lojas próprias, a pesquisa de Carmo (2012), identificou que o volume das vendas realizadas no atacado é bem representativo; porém, quando verificou a sua diferença, em relação ao volume de vendas no varejo, o resultado não foi muito significativo, sobressaindo-se a venda em varejo. Este fato se explica pela presença da indústria no município, pois o lojista, ou o revendedor, bem como qualquer consumidor, quando possui a intenção de realizar a compra no atacado, desloca-se em direção à própria fábrica.

As lojas de fábrica, apesar de Carmo (2012) ter verificado que algumas localizam-se nas ruas da cidade, concentram-se, em maioria, no Shopping do 
Calçado, este que teve sua implantação como uma iniciativa de divulgação e de promoção do APL e que recebe consumidores, em maior porcentagem, de outras cidades do Estado de São Paulo.

A constatação feita pela autora, da presença reduzida de calçados nos estabelecimentos de comércio especializado, localizados nas ruas do centro de Franca, bem como das indústrias procurarem manter suas lojas, a direcionou ao entendimento de que a relação entre os produtores de calçados e os comerciantes de varejo especializados locais é incipiente ou quase nula.

Pode-se dizer que em Franca se configura um monopólio estabelecido pelas indústrias no que se refere à comercialização de seus calçados no município. Este fato sendo analisado, em conformidade com Suzigan, Garcia e Furtado (2005), pode ser considerado como ponto positivo para a indústria calçadista, haja vista ela controlar os ativos de distribuição. Entretanto, há de considerar que a concentração do capital, gerado tanto na produção como no comércio dos produtos do APL, pelos industriais; e, o comércio local sendo pouco beneficiado, culmina, segundo Carmo (2012) com uma relação de concorrência entre eles pelo mercado varejista.

As transformações ocorridas no processo produtivo nas décadas finais do século $X X$ condicionaram o estreitamento das relações entre a indústria e o comércio, sendo que as atividades de ambos são realizadas em uma dependência mútua. Contudo, a relação entre tais setores da economia, em Franca, como já especificado, por meio da análise da pesquisa de Carmo (2012), ocorre por meio de monopólio da indústria sobre a comercialização de seus produtos.

As análises empreendidas por Carmo (2012) também privilegiaram os outros níveis da cadeia de valor da produção de calçado em Franca, como a concepção do produto e a publicidade.

\subsection{A Concepção do Produto e a Publicidade no Arranjo Produtivo Local Calçadista de Franca (SP)}

Giles Lipovetsky é um autor que dedicou grande parte de sua produção bibliográfica à reflexão sobre a moda e em sua obra de 1989, ele explica que, 
na atualidade, é possível verificar a valorização do "presente" e do "Novo". Nesse contexto, destaca-se o papel do design, qual seja: incorporar ao produto uma aparência de Novo por meio da inserção de aspectos aparentemente arrojados e modernos, atuais.

Fica claro então que no momento da concepção do produto, fatores como design e moda devem ser considerados pelo profissional da área, no momento da criação, pois somente dessa forma o produto poderá ser reconhecido e valorizado, além de conseguir sua manutenção no mercado.

Trazendo tais reflexões para o setor calçadista, é possível identificar a necessidade do investimento na criação, com o intuito de incorporar as inovações na produção, de modo a obter-se um calçado diferenciado, com alto valor agregado, podendo adentrar mercados segmentados, especialmente na atualidade, cuja competição com o produto asiático, especialmente chinês, em preço, é impossível. Portanto, essa competição deverá ser levada para outro patamar, cuja qualidade e inovação devem ser prioridade.

Para obter-se êxito nos mercados, as indústrias precisam investir na aquisição de conhecimentos referentes a toda a cadeia de valor, manter interrelações com os agentes dos processos iniciais, como a moda, o design, o marketing, a publicidade, bem como com aqueles responsáveis pelos processos finais, especialmente, pelos canais de distribuição.

Em análise às ações das indústrias calçadistas de Franca sobre o investimento em inovação e em desenvolvimento de design moderno, Carmo (2012) identificou que a criação de novos produtos é realizada, de forma individual, ou seja, por indústria, e não no âmbito da governança do Arranjo Produtivo Local. As indústrias, em sua maioria, contratam empresas no próprio município para realizarem essa tarefa.

Em relação à liberdade de criação, o levantamento de Carmo (2012) apontou que seis indústrias possuem liberdade de criar seus modelos, sendo que estas possuem acesso aos mercados regional, nacional e internacional. Três indústrias atuam em todos os mercados, porém somente no nacional e no regional é que há a inserção de modelos de criação própria; no mercado internacional, o produto oferecido é aquele produzido com as especificações do 
cliente, ou seja, daquele que vai atuar no comércio externo. O restante das indústrias investigadas não atua no mercado externo, tendo, portanto, liberdade de criação.

Ao averiguar, detalhadamente as indústrias que atuam no mercado externo, a autora supracitada, identificou que a maior parte atua com marca própria; contudo, ao analisar o volume de vendas, verificou que este é pouco superior ao daquelas que atuam com a marca dos clientes.

De acordo com as informações levantadas por Carmo (2012), o investimento em design e em inovação, para a concepção do calçado, é feito majoritariamente de forma individual, pelas indústrias. Entretanto, como já explicitado anteriormente, Arranjos Produtivos Locais são formados essencialmente por micro e pequenas indústrias, sendo que em Franca não há exceção. As indústrias de dimensões menores não possuem recursos financeiros suficientes para investir no setor de criação, ficando este em defasagem.

Outro fator importante da cadeia de valor de um produto que merece destaque é a publicidade. Há que se dizer que na atualidade as estratégias de publicidade seguem a lógica da "mercadoria-signo", de modo a proporcionarem ao consumo um novo significado.

Sobre a "mercadoria-signo", Baudrillard (1995) expõe que, na sociedade atual, a mercadoria é repleta de carga simbólica, o seu consumo visa muito mais que uma simples satisfação das necessidades, dos desejos; ela própria se torna uma forma de comunicação.

Mesmo com a importância da publicidade para a comercialização dos produtos, o SindiFranca, segundo Carmo (2012), alega a pouca disponibilidade de recurso para atender a esse setor. A divulgação dos calçados é realizada por meio de jornal, de circulação local, site do sindicato e de e-mail.

O que é mais recorrente no APL, ainda em análise aos dados levantados por Carmo (2012), são as indústrias promoverem a publicidade individualmente, cada uma de acordo com seus recursos. Algumas investem na publicação de revistas, anualmente, outras bimestralmente, apresentando 
então as novas coleções. Outros meios de publicidade utilizados, e que se destacam no espaço urbano de Franca, são os outdoors e os carros de som.

Como pôde ser notado, vários são os meios utilizados pelas indústrias do APL para divulgarem seus calçados; no entanto, em razão dos poucos recursos disponíveis, a divulgação, por parte da maioria delas, ainda é incipiente. Embora haja algumas ações adotadas pelo APL, entretanto, elas funcionam indiretamente como meio de publicidade, como é o caso tanto da participação nas feiras do setor calçadista, quanto da criação do Shopping do Calçado.

As feiras técnicas são eventos organizados com o principal objetivo de promover e divulgar produtos; entretanto, pode ocorrer, durante sua realização, a formalização de encomendas para a produção.

Censi (2004) realizou um levantamento bibliográfico importante sobre as feiras setoriais, possibilitando a identificação de que, além da exposição e da venda, a participação em feiras proporciona aos expositores mais cinco vantagens, quais sejam: manter contato direto com clientes; desenvolver um mailing (um banco de dados para os diversos segmentos de mercado) de prospecção; coletar informações sobre a concorrência; lançar novos produtos; e, por fim, estabelecer novos contatos comerciais, ou seja, futuros parceiros.

O esclarecimento, apresentado pela autora acima, evidencia a importância da participação nas feiras setoriais pelas indústrias, principalmente quando se almeja a inserção dos produtos em novos mercados, especialmente no internacional, pois se vê que elas desempenham o mesmo papel que as vitrines, cujos produtos são expostos aos olhos dos visitantes.

A participação das indústrias de Franca nas feiras do setor calçadista, conforme Carmo (2012), ocorre individualmente e por meio do estande coletivo denominado "Espaço Moda Franca". A participação na feira, por meio do estande coletivo, é subsidiada pelo Sebrae-SP, que fica responsável por $40 \%$ do custo, destinando-o à montagem e aos gastos com energia elétrica, enquanto a porcentagem restante das despesas é dividida entre a Prefeitura Municipal e as indústrias expositoras, cujo apoio recebido para a participação nas feiras é de suma importância, pois sem esse recurso, muitas das pequenas 
e micro indústrias não teriam condições de participar da exposição.

A mesma autora explica que a contribuição por parte da Prefeitura Municipal para a participação das indústrias do APL de Franca nas feiras setoriais, só foi possível graças à criação da LEI № 7.261, de 02 de julho de 2009, que a autoriza a celebrar convênios com entidades, objetivando a transferência de recursos para a locação de estandes em apoio ao seu setor industrial calçadista.

Em análise mais detalhada, Carmo (2012) pôde esclarecer que as indústrias que participam individualmente, comprando suas áreas para montarem seus estandes são de porte que vai de pequeno a grande, pois essa participação não depende da dimensão da indústria e sim da condição financeira de cada uma, bem como de suas prioridades e de suas estratégias para a promoção de seus produtos.

A autora levantou ainda que as motivações das indústrias para participarem nas feiras são: expandir o mercado; buscar novos clientes através da divulgação de seus produtos; averiguar as tendências da moda couro; e, por fim, a realização de vendas. Portanto, pode-se entender que a participação nas feiras do setor representa, principalmente, a oportunidade de divulgação dos calçados de Franca, sendo que os negócios realizados durante esse evento, além de gerarem demandas à produção, movimenta a economia do município.

Conforme especificado linhas acima, outro meio de divulgação dos calçados produzidos em Franca é o Shopping do Calçado. Este foi criado, segundo Carmo (2012) em 1997, como uma estratégia para a promoção e a divulgação do calçado francano. Nesse espaço, há uma concentração de lojas de fábrica, atuando na comercialização de sapatos, bem como de estabelecimentos comerciais de comércio varejista especializado em calçado.

Carmo (2012) destaca que embora haja a concentração de estabelecimentos comerciais especializados no comércio de calçados, no shopping em questão, o número deles é reduzido em relação ao total de lojas em funcionamento no local. Este fato chama a atenção em razão do nome do empreendimento sugerir que aí se encontre somente o comércio de calçados e artefatos de couro; contudo, o que se verifica é a presença maciça de lojas 
tradicionais, voltadas ao comércio em geral, como ocorre em qualquer shopping.

A pesquisa de Carmo (2012) evidencia que apesar da leitura especializada indicar a importância e a necessidade de maior integração entre as indústrias do APL e os agentes de sua governança, que no caso de Franca é o sindicato (SindiFranca), há uma ausência de cooperação.

Essa falta de cooperação já foi constatada em estudos acadêmicos relacionados à APLs, havendo, por isso, conforme Carmo (2012), a necessidade da atuação do SindiFranca no sentido de elevar a cooperação entre as indústrias, pois somente assim é que aquelas de pequena e micro dimensões poderão crescer significativamente e estabelecerem-se em todos os mercados com marca própria.

Santos, Diniz e Barbosa (2004) defendem que por meio da governança, com planejamento de suas ações, o APL pode alcançar uma cooperação multilateral e institucionalizada, tornando-se forte o suficiente para reagir coletivamente às ameaças e oportunidades. Contudo, em Franca, muitos dentre os proprietários não se envolvem coletivamente em atividades do âmbito do APL.

A partir da retomada da pesquisa de Carmo (2012), juntamente com novas leituras e reflexões, pode-se inferir que, apesar da necessidade de investimento nos processos iniciais e finais da cadeia de valor do produto, pouco tem sido realizado no APL de Franca nesse sentido e que a relação entre a indústria e os estabelecimentos comerciais, principalmente em nível local, é incipiente, bem como a indústria, além de atuar com o comércio atacadista, também atua na realização do comércio varejista, monopolizando a comercialização de seus produtos.

\section{CONSIDERAÇÕES FINAIS}

Neste texto, procurou-se apresentar as dinâmicas da relação comércioindústria, destacando o caso do Arranjo Produtivo Local calçadista de Franca (SP), alvo da pesquisa de Carmo (2012). A análise da evolução do APL possibilitou identificar que o seu bom desempenho no comércio contribuiu para 
seu desenvolvimento e sua consolidação, pois foi somente a partir da conquista gradativa dos mercados local, regional, nacional e internacional que houve sua evolução, fato que evidencia a necessidade de elevar a relação entre todos os agentes envolvidos na cadeia de valor do produto, cujo investimento direcionado aos outros setores, além do produtivo, por parte das indústrias, ainda é muito pouco.

Em Franca, a venda a varejo dos calçados de produção local é realizada localmente e, em maior escala, por lojas próprias, ou diretamente na fábrica, sendo mínima sua realização em estabelecimentos comerciais independentes na cidade. Essa constatação indica que há pouca relação entre as indústrias e o comércio local, havendo um controle, um monopólio daquelas sobre a comercialização do calçado. Manter o controle sobre os canais de distribuição é entendido como uma estratégia importante para os produtores; entretanto, essa atitude contribui para o não estreitamento das relações com os comerciantes locais.

É fato que o comércio local não é prioridade para as indústrias de Franca. Elas priorizam o comércio em nível nacional e internacional. Tal negligência em relação ao mercado local promove a não articulação entre produtores e comerciantes locais. Porém, tem-se o entendimento de que a relação das indústrias calçadistas com o município não devesse se estabelecer somente para o uso de seu espaço e de sua população como mão de obra.

Ao realizar este apontamento, volta-se também para a reflexão sobre a importância dada aos APLs, quando alguns autores defendem que eles promovem a articulação entre os diversos atores de determinado território, proporcionando o desenvolvimento local e regional. Entende-se que esse desenvolvimento é tomado somente no que concerne ao crescimento econômico e não relacionado ao desenvolvimento social.

Analisando o caso de Franca, percebe-se que o desenvolvimento promovido pelo APL é apenas em nível econômico, sendo este alcançado apenas pelos detentores da produção, embora se entenda que os comerciantes locais também apresentam desenvolvimento econômico, mas não em função da relação com as indústrias locais. 
O capital gerado com a produção industrial do APL não beneficia a população francana, a não ser pela geração de emprego. Entretanto, as funções aí desempenhadas por ela não possuem uma remuneração alta, pois os trabalhos são manuais, não exigindo, a princípio, especialização formal (cursos e capacitações) por parte do trabalhador, embora seja muito bem qualificado por meio de treinamentos técnicos na unidade de produção e, também, propiciados pela experiência dada pelo próprio trabalho, principalmente em razão da atmosfera gerada pela produção local, o chamado transbordamento de conhecimento (spillover).

Essas dinâmicas da relação entre indústria e comércio em Franca são materializadas e fragmentadas no espaço urbano. Isto pode ser verificado quando se observa que pelo comércio do centro da cidade não é possível a percepção de que tipo de mercadoria é produzido no APL. O comércio local apresenta características comuns aos de outras cidades, pois não há um vínculo especial com as indústrias de calçados. A importância dessa produção em Franca é percebida somente pelas unidades produtivas, por meio da presença das lojas de fábrica, que se concentram no Shopping do Calçado, e dos outlets, que não perfazem um número significativo e se localizam em avenidas de grande circulação; e, por fim, pela geração de emprego nas unidades produtivas.

\section{REFERÊNCIAS}

BAUDRILLARD, J. A sociedade de consumo. Lisboa: Edições 70, 1995.

BENKO, G. Economia, espaço e globalização: na aurora do século XXI. Tradução Antônio de Pádua Danesi. São Paulo: Hucitec, 1996.

$\mathrm{CACHINHO}, \mathrm{H}$. Geografias do Consumo: rotas exploradas e novas linhas de rumo. Inforgeo, 14, Lisboa, Edições Colibri, 1999, p. 157-178.

CARMO, J. A.; ORTIGOZA, S.A.G. O estudo do comércio no contexto da dinâmica dos Arranjos Produtivos Locais. In: I CONGRESSO BRASILEIRO DE ORGANIZAÇÃO DO ESPAÇO E X SEMINÁRIO DE PÓS-GRADUAÇÃO EM GEOGRAFIA. Rio Claro: UNESP, 2010. 2672- 2688. CD Disponível em: $<\mathrm{http}: / /$ www.cboe.tk/>. 
CARMO, J. A. O Comércio no Arranjo Local Calçadista de Franca (SP). 2012. 222 f. Tese (Doutorado em Geografia) - Instituto de Geociências e Ciências Exatas, Universidade Estadual Paulista "Julio de Mesquita Filho", Rio Claro, 2012.

CARMO, J. As articulações entre comércio e distribuição na dinâmica da produção em aglomerado produtivo calçadista de Portugal. GEOUSP - Espaço e Tempo (Online), São Paulo, v. 18, n. 1, p. 83-96, 2014.

CASSIOLATO, J. E. LASTRES, H. M. M. Arranjos e Sistemas Produtivos Locais na Indústria Brasileira. Revista de Economia contemporânea. Instituto de Economia, UFRJ, V. 5, n. especial, p. 1-37, 2001.

CASSIOLATO, J. E.; LASTRES, H. M. M. Arranjos e Sistemas Produtivos Locais e Proposições de Políticas de Desenvolvimento Industrial e Tecnológico. Rio de Janeiro, REDESIST, Bloco 3, Nota Técnica 27, Dezembro de 2000. Disponível em: <http://www.ie.ufrj.br>. Acesso em 02 jul.2008.

\section{CENSI, J. F. A Participação em Feiras de Negócio como Importante} Estratégia Organizacional. 2004. 122f. Trabalho de Conclusão de Curso (Bacharelado em Comunicação Social) - Escola de Comunicação e Arte. Universidade de São Paulo, São Paulo, 2004. Disponível em:<http://www.rpbahia.com.br/biblioteca/academicos/paper/monografias/feiras_de_negocios.pdf >. Acesso em 20 jul.2012.

CLEPS, G. D. G. Estratégias de reprodução do capital e as novas espacialidades urbanas: o comércio de auto-serviço em Uberlândia (MG). 2005. 181 f. Tese (Doutorado em Geografia)- Instituto de Geociências e Ciências Exatas, Universidade Estadual Paulista "Júlio de Mesquita Filho", Rio Claro, 2005.

FUNDAÇÃO SISTEMA ESTADUAL DE ANÁLISE DE DADOS (SEADE). Índice Paulista de Responsabilidade Social. Disponível em: <http://www.iprsipvs.seade.gov.br/view/index.php?prodCod=1>. Acesso em 15 maio. 2011.

HARVEY D. Condição pós-moderna. Uma pesquisa sobre as origens da mudança cultural. Tradução de Adail Ubirajara Sobral e Maria Stela Gonçalves. 9‥ ed. Rio de Janeiro: Loyola, 1992.

INSTITUTO BRASILEIRO DE GEOGRAFIA E ESTATÍSTICA. Censo Demográfico 2010. Disponível em: <http://censo2010.ibge.gov.br/>. Acesso em 12 maio. 2011.

INSTITUTO DE ESTUDOS E MARKETING INDUSTRIAL (IEMI). Estudo Sobre o Setor de Calçados de Franca e Região. Fev/2011. Disponível em: <http://www.sindifranca.org.br/edicoes_revista/marco2011/catalogo.html>. Acesso em diversas datas. 
LASTRES, H. M. M.; CASSIOLATO, J. E. Mobilizando conhecimentos para desenvolver arranjos e sistemas produtivos e inovativos locais de micro e pequenas empresas no brasil. Glossário de Arranjos e Sistemas Produtivos e Inovativos Locais. Projeto, Apoio: SEBRAE, 8. Revisão, 2005.

LEFEBVRE, H. Lógica Formal, Lógica Dialética. Rio de Janeiro: Civilização brasileira, 1995.

LIPOVETSKY, G. O Império do efêmero: a moda e seu destino nas sociedades modernas. Tradução de Maria Lucia Machado. São Paulo: Companhia das Letras, 1989.

MENDES, A. A. Reestruturações locais como efeitos da globalização econômica: uma análise da estrutura produtiva mutante do pólo têxtil de Americana- SP. 1997. 194 f. Tese (Doutorado em Geografia) - Instituto de Geociências e Ciências Exatas, Universidade Estadual Paulista "Júlio de Mesquita Filho, Rio Claro, 1997.

ORTIGOZA, S. A. G. As franquias e as novas estratégias do comércio urbano no Brasil. 1996. 180 f. Dissertação (Mestrado em Geografia) - Instituto de Geociências e Ciências Exatas, Universidade Estadual Paulista "Júlio de Mesquita Filho", Rio Claro, 1996.

PINTAUDI, S. M. Shopping Center no Brasil: Condições de Surgimento e Estratégia de Localização. In: FRÚGOLI JR. H.; PINTAUDI, S. (orgs.)

Shopping Centers: espaço, cultura e modernidade nas cidades brasileiras. São Paulo: Editora da Unesp, 1992. p. 15-44.

SALGUEIRO, T. B. Do comércio a distribuição: Roteiro de uma mudança. Oeiras. Celta, 1996.

SAMPAIO, S. S. Indústria e território em São Paulo: A estruturação do Multicomplexo Territorial Industrial Paulista: 1950-2005. Campinas: Alínea, 2009.

SANTOS, G. A. G.; DINIZ, E. J.; BARBOSA, E. K. Aglomerações, Arranjos Produtivos Locais e Vantagens Competitivas Locacionais. Revista do BNDES, v.11, n. 22, p. 151-179, 2004.

SINDIFRANCA. Resenha Estatística. Mar/2011. Disponível em: < http://www.sindifranca.org.br/downloads/Resenha\%20Estat\%C3\%ADstica\%20 Mar\%C3\%A7o\%2011.pdf>Acesso em 18 abr.2011.

SUZIGAN, W.; GARCIA, R.; FURTADO, J. Sistemas Locais de Produção/Inovação: Metodologia para Identificação, Estudos de Casos e Sugestões de Políticas. In: DINIZ, C.C.; LEMOS, M. B. (Orgs.). Economia e território. Belo Horizonte: Editora UFMG, 2005. p. 287-320. 
TEIXEIRA, D. J. A descentralização do comércio varejista de Belo Horizonte. 2000. $312 \mathrm{f}$. Tese (Doutorado em Geografia) - Instituto de Geociências e Ciências Exatas, Universidade Estadual Paulista "Julio de Mesquita Filho", Rio Claro, 2000.

TRIVIÑOS, A. N. S. Introdução à pesquisa em Ciências Sociais à pesquisa qualitativa em educação. São Paulo: Atlas, 1987.

VERDI, A. R.; PIRES, E. L. S. As dinâmicas territoriais locais na globalização: aspectos conceituais e metodológicos . Geosul. Florianópolis, v. 23, n. 46, p 33-53, jul/dez. 2008. 